\title{
Efficacy of a third coronary angioplasty for a second restenosis: short-term results, long-term follow up, and correlates of a third restenosis
}

\author{
Kim H Tan, Neil Sulke, Nick Taub, S Karani, E Sowton
}

\begin{abstract}
Objective-To report on the short-term and long-term results of patients who underwent $a$ third coronary balloon angioplasty for a second restenosis and to identify the correlates of a third clinical restenosis.

Design-A retrospective analysis of clinical, angiographic, and procedure related variables of a consecutive series of patients.

Patients -62 patients (mean (range) age 53 (31-72) years; 84\% men) who underwent a third coronary balloon angioplasty of a single coronary artery segment at which restenosis had occurred after two previous angioplasty procedures between 1986 and 1992.
\end{abstract}

Results-Procedure success was achieved in 56 patients (90\%). Complications included one myocardial infarction (2\%) and one emergency coronary artery bypass surgery (2\%). Complete follow up data were available (median (range) 48 (12-94) months). During the follow up period, four patients (6\%) died, two (3\%) had a non-fatal myocardial infarction, and five $(8 \%)$ underwent elective coronary artery bypass surgery. Nine patients (14\%) underwent a fourth angioplasty for a third clinical restenosis, and three (5\%) had a fourth angioplasty procedure for new coronary lesions. The cumulative probability of survival for all 62 patients was $97 \%$ and $95 \%$ at 1 and 5 years, respectively. The 1 and 5 year freedom from death, infarction, bypass surgery, and repeat angioplasty was $82 \%$ and $66.6 \%$, respectively. At census, of the 58 survivors, 31 (53\%) were asymptomatic and only eight (14\%) complained of angina grade III or IV $(P<0.001)$. A third clinical restenosis occurred in 22 $(39 \%)$ of the 56 patients who had initially successful procedures. Multiple stepwise logistic regression analysis identified the interval between the second and third angioplasty procedure as the only independent predictor of a third clinical restenosis $(P=0.004)$.

Conclusions-A third coronary angioplasty for a second restenosis can be performed safely and effectively and should be considered as an integral part of the overall coronary angioplasty revascularisation strategy. The incidence of a third clinical restenosis remains high, how- ever, and is correlated with the interval between the previous angioplasty procedures.

(Br Heart f 1995;73:327-333)

Keywords: recurrent restenosis; revascularisation; balloon angioplasty

Despite continuing improvement in primary success rate restenosis remains the major limitation of percutaneous transluminal coronary angioplasty. The reported incidence ranges from $16 \%$ to $47 \%$ depending on the population studied. ${ }^{1-3}$ The efficacy of a second coronary angioplasty for a first restenosis has been well documented, and earlier studies have reported higher acute success and lower complication rates than those usually reported for a first angioplasty. ${ }^{4-6}$ Hence, treatment of restenosis with a repeat angioplasty has become routine clinical practice, and is currently accepted as an integral part of the overall coronary angioplasty revascularisation strategy. ${ }^{7-9}$

Although a second recurrence is no more likely than a first, restenosis after a second angioplasty is nevertheless associated with an incidence ranging from $26 \%$ to $34 \%$ in previously reported series. ${ }^{10-12}$ Patients with restenosis after a second angioplasty will become an increasing clinical problem as growth in the volume of angioplasties continues. Although a third angioplasty for a second restenosis has been shown to be technically feasible and safe, information about late outcome is limited. ${ }^{13-15}$ Whether these patients should be subjected to a third angioplasty, or whether coronary artery bypass grafting is the preferred mode of revascularisation at this stage remains unanswered. In addition, the ability to identify those patients at higher risk of a subsequent restenosis will have important implications in planning and optimising individual therapeutic strategy.

To resolve some of these issues, this study reports on the acute success and long-term follow up of patients who underwent a third coronary balloon angioplasty for a second restenosis. The correlates of clinical restenosis after a third angioplasty were also examined.

\section{Patients and methods}

PATIENTS

Between January 1986 and December 1992, 62 patients underwent a third percutaneous 
transluminal coronary balloon angioplasty of a single coronary arterial segment at which restenosis had occurred after two previous angioplasties. Patients who had their third angioplasty within two weeks of the preceding procedure were not included in the study to exclude patients who had repeat dilatation because of periprocedural complication. The median (range) time interval between the second and the third angioplasty was 6 (1-22) months.

The mean (SD) (range) age was 53 (9) (31-72) years and $52(84 \%)$ were male (table $1)$. Thirty patients $(48 \%)$ had a history of previous myocardial infarction and $22(35 \%)$ had impaired left ventricular function with an ejection fraction of $<45 \%$ assessed by contrast ventriculography. Twelve patients $(19 \%)$ had undergone previous coronary artery bypass grafting. Coronary angioplasty was performed as an emergency for unstable angina in 10 patients $(16 \%)$. Some 47 patients $(76 \%)$ suffered angina grade III or IV as assessed by the Canadian Cardiovascular Society functional classification before intervention. ${ }^{16}$ Thirty seven patients $(60 \%)$ had multivessel disease, 11 (18\%) underwent multivessel coronary angioplasty, and $16(26 \%)$ underwent multilesion coronary angioplasty during the same procedure. A mean of 1.2 vessels and 1.4 stenoses per patient was attempted. Risk factors present in the patients included hypertension (23\%), diabetes mellitus (10\%), hypercholesterolaemia (47\%), and current smoking (60\%).

\section{ANGIOPLASTY}

Coronary angioplasty was performed according to a previously described protocol. ${ }^{17}$ The

Table 1 Baseline characteristics of all 62 patients

\begin{tabular}{lc}
\hline & No \\
\hline Male gender & $52(84)$ \\
Previous MI & $30(48)$ \\
Angina grade & $2(3)$ \\
O/I & $13(21)$ \\
II & $23(37)$ \\
III & $24(39)$ \\
IV & $10(16)$ \\
Unstable angina & $22(35)$ \\
Abnormal LV (EF <45\%) & \\
Number of diseases vessels & $25(40)$ \\
1 & $26(42)$ \\
2 & $11(18)$ \\
3 & $12(19)$ \\
Previous CABG & $11(18)$ \\
Multivessel PTCA & $16(26)$ \\
Multilesion PTCA & \\
Dilation site & $28(45)$ \\
LAD & $6(10)$ \\
CX & $12(19)$ \\
RCA & $5(8)$ \\
SVG & $5(8)$ \\
LAD and CX & $5(8)$ \\
LAD and RCA & $1(2)$ \\
LAD, CX, and RCA & $14(23)$ \\
Risk factors & $6(10)$ \\
Hypertension & $37(60)$ \\
Diabetes mellitus & $29(47)$ \\
Current smoking & $23(37)$ \\
Hypercholesterolaemia & \\
Family history of CAD & \\
\hline
\end{tabular}

Values in parentheses are percentages.

CABG, coronary artery bypass surgery; $\mathrm{CAD}$, coronary artery disease; $\mathrm{CX}$, circumflex artery; $\mathrm{EF}$, ejection fraction; $\mathrm{LAD}$, left anterior descending artery; LV, left ventricular function; MI, myocardial infarction; PTCA, percutaneous transluminal coronary angioplasty; RCA, right coronary artery; SVG, coronary angioplasty;
saphenous vein graft. femoral approach was used in all cases. All patients received oral aspirin and most patients were sedated with intravenous diazepam. A total of 10000 units of intraarterial heparin were administered at the start of the procedure. Additional boluses were given to maintain an activated clotting time of $>300$ s. Adaptations were made to accommodate technical advances such as the development of low profile, steerable balloon catheters throughout the study period. Balloon size was selected to approximate the diameter of the adjacent normal segment of the coronary artery. Intravenous infusions of heparin and nitrate were continued for $24 \mathrm{~h}$ after angioplasty.

A total of 74 vessels and 85 stenoses were attempted during the same procedure. Of the 62 coronary artery segments dilated for the third time for a second restenosis, $33(53 \%)$ were located in the left anterior descending artery and its diagonal branches, nine (15\%) in the circumflex artery and its obtuse marginal branches, $15(24 \%)$ in the right coronary artery, and five ( $8 \%$ ) in saphenous vein grafts. Three procedures were undertaken for totally occluded vessels. Of the remaining 23 stenoses dilated in those patients who underwent multilesion angioplasty, 18 were dilated for the first time and five for the second time.

\section{METHODS}

The baseline clinical, angiographic, and procedural data of the 62 patients were assessed. Angiographic details were assessed by two independent observers. The opinion of a third experienced cardiologist was obtained if there was disagreement. Quantitative measurements were made using hand held callipers on projected angiographic film using the image of the guiding catheter for magnification scaling. A protractor was used for measuring lesion angulation. Lesion complexity was classified as type $\mathrm{A}, \mathrm{B} 1, \mathrm{~B} 2, \mathrm{C} 1$, or $\mathrm{C} 2$ using the morphological characteristics initially described by the American Heart Association/American College of Cardiology Task Force as modified by Ellis $e t a l^{18}$ and Myler et al. ${ }^{19}$ On the basis of these criteria, of the 62 lesions that underwent a third angioplasty procedure, $16(26 \%)$ were classified as type A, $17(27 \%)$ as type B1, 13 (21\%) as type B2, $15(24 \%)$ as type $\mathrm{C} 1$, and one $(2 \%)$ as type $\mathrm{C} 2$.

Complete follow up data obtained at routine clinic visits, from the referring physicians, and by telephone interview with the patients were available for the 62 patients. All patients were eligible for at least six months' follow up after the procedure. Information on vital status, angina status, and the occurrence of new cardiac events (defined as myocardial infarction, coronary artery bypass grafting, or repeat coronary angioplasty) was obtained. At our centre patients are followed closely by functional testing for the development of symptoms or signs of myocardial ischaemia after angioplasty. The indication for follow up coronary angiography was strictly clinical: recurrence of angina pectoris, or a positive symptom limited treadmill 
exercise test performed routinely during outpatient visits.

The patient related variables analysed as possible determinants of restenosis included age, sex, angina grade, presentation with unstable angina, extent of coronary artery disease, left ventricular function, and the time interval between second and third angioplasty. Other variables considered were a history of smoking, hypertension, diabetes mellitus, hypercholesterolaemia, previous myocardial infarction, previous coronary artery bypass surgery, and presence of family history. The lesion related variables analysed as possible determinants of restenosis included lesion length, eccentricity, angulation, contour, calcification, and location (ostial, proximal, mid, or distal). Other variables considered were vessel diameter, vessel location, pre-angioplasty percentage stenosis, post-angioplasty percentage stenosis, presence of distal ectasia, presence of thrombus, and presence of post-angioplasty dissection. The procedure related variables analysed as possible determinants of restenosis included the number of inflations, maximum inflation pressure, maximum inflation duration, total inflation duration, and balloon to artery ratio.

\section{DEFINITIONS}

Procedural success was defined as $\leqslant 50 \%$ residual diameter stenosis at the dilated sites without a major complication (invariably the result of an abrupt occlusion of the vessel being dilated), defined as death, myocardial infarction, or emergency coronary artery bypass grafting, at any time during hospitalisation. Success was judged in patients who underwent multivessel or multilesion coronary angioplasty according to the outcome of the coronary artery segment dilated for the third time for a second restenosis. If a significant inhospital complication occurred as a result of dilating another lesion despite angiographic success for the coronary artery segment which had recurrent restenosis, however, the procedure was judged to be a failure. Angiographic restenosis was defined as a recurrence of a $>50 \%$ diameter stenosis at a previously successfully dilated site. Clinical restenosis was defined as the recurrence of anginal symptoms or evidence of reversible ischaemia associated with angiographic evidence of restenosis. Patients who had a cardiac death or a non-fatal myocardial infarction during the follow up period were also considered as having had a clinical restenosis. Unstable angina pectoris was defined as angina occurring at rest requiring intravenous medical treatment and included patients with post-infarction angina pectoris.

\section{STATISTICAL ANALYSIS}

Continuous variables are expressed as mean (SD). For the purpose of assessing determinants of a third restenosis the unit of analysis used is the stenotic lesion, not the patient. Restenosis was analysed as a dichotomous variable for each lesion. The recurrence rates were assessed for all variables analysed as possible correlates of restenosis.

The relation of categorical variables to the restenosis rate was examined using the $2 \times 2$ $\chi^{2}$ test or Fisher's exact test. Continuous variables were grouped into two approximately equally sized subgroups according to the values of each variable. The relation between restenosis rate and these subgroups was also analysed using the $2 \times 2 \chi^{2}$ or Fisher's exact test. $\mathrm{P}<0.05$ was considered significant. All variables found to be significantly related to restenosis by univariate analysis were included in a multiple logistic regression analysis. The backward stepwise selection procedure was used to identify independent predictors of procedural outcome significant at the $1 \%$ level (BMDP program LR). Survival functions were estimated using the Kaplan-Meier method (BMDP program 1L) computed from the time of coronary angioplasty.

\section{Results}

ACUTE RESULTS

Procedural success was achieved in 56 patients $(90 \%)$. Mean (SD) stenosis was reduced from 83 (13)\% to 12 (9)\%. A major inhospital complication occurred in two patients $(3 \%)$. One patient $(2 \%)$ suffered a non-fatal myocardial infarction based on electrocardiographic and enzyme changes and one $(2 \%)$ underwent emergency coronary artery bypass grafting due to intimal dissection followed by abrupt closure. No procedural deaths occurred.

\section{LONG-TERM RESULTS}

Complete follow up data were available for the 62 patients on or after the census date. The median (range) duration of follow up was 48 (12-94) months. During the follow up period, four patients $(6 \%)$ died, two $(3 \%)$ suffered a non-fatal myocardial infarction, and five $(8 \%)$ underwent elective coronary artery bypass grafting. Nine patients (14\%) underwent a fourth angioplasty for a third restenosis and three (5\%) had a fourth angioplasty for new coronary lesions. Overall, a second revascularisation procedure was necessary in 17 patients $(27 \%)$. The four late deaths included two cardiac deaths (one sudden death and one fatal myocardial infarction), one from elective coronary artery bypass grafting for restenosis, and one from repeat angioplasty for new coronary lesions.

The cumulative probability of survival for all 62 patients was $96 \cdot 8 \%$ (SE $2 \cdot 2$ ) at 1 year and $95.0 \%$ (SE $2 \cdot 8$ ) at 5 years after percutaneous transluminal coronary angioplasty (PTCA) (table 2). Both the 1 and 5 year cumulative survival rates for patients with initially successful angioplasties were $96 \cdot 2 \%$ (SE $2 \cdot 7)$. Table 2 gives total and event free survival rates at 1 and 5 years after PTCA for all patients, and those with initially successful procedures, while figure 1 shows the total and event free survival rates for $0-5$ years after PTCA for all patients and figure 2 survival 
Table 2 Total and event free survival at 1 and 5 years after coronary angioplasty (PTCA) for all patients and patients with clinically successful procedures

\begin{tabular}{|c|c|c|c|c|}
\hline & \multicolumn{2}{|c|}{ One year after PTCA } & \multicolumn{2}{|c|}{ Five years after $P T C A$} \\
\hline & All patients & $\begin{array}{l}\text { Clinically } \\
\text { successful }\end{array}$ & All patients & $\begin{array}{l}\text { Clinically } \\
\text { successful }\end{array}$ \\
\hline $\begin{array}{l}\text { Survival (freedom } \\
\text { from death) }(\%)\end{array}$ & $\begin{array}{l}96 \cdot 8 \\
(92 \cdot 3-100)\end{array}$ & $\begin{array}{l}96 \cdot 2 \\
(90 \cdot 9-100)\end{array}$ & $\begin{array}{l}95 \cdot 0 \\
(89 \cdot 4-100)\end{array}$ & $\begin{array}{l}96 \cdot 2 \\
(90 \cdot 9-100)\end{array}$ \\
\hline Freedom from death/MI (\%) & $\begin{array}{l}95 \cdot 2 \\
(89 \cdot 7-100)\end{array}$ & $\begin{array}{l}96 \cdot 2 \\
(90 \cdot 9-100)\end{array}$ & $\begin{array}{l}90.9 \\
(82.9-98.9)\end{array}$ & $\begin{array}{l}93 \cdot 2 \\
(85 \cdot 5-100)\end{array}$ \\
\hline $\begin{array}{l}\text { Freedom from death/ } \\
\text { MU/CABG }(\%)\end{array}$ & $\begin{array}{l}93 \cdot 6 \\
(87 \cdot 4-99 \cdot 8)\end{array}$ & $\begin{array}{l}94 \cdot 2 \\
(87 \cdot 7-100)\end{array}$ & $\begin{array}{l}83 \cdot 1 \\
(72 \cdot 6-93 \cdot 6)\end{array}$ & $\begin{array}{l}84 \cdot 0 \\
(72 \cdot 6-95 \cdot 4)\end{array}$ \\
\hline $\begin{array}{l}\text { Freedom from death/ } \\
\text { MI/CABG/PTCA (\%) }\end{array}$ & $\begin{array}{l}82 \cdot 3 \\
(72 \cdot 6-92)\end{array}$ & $\begin{array}{l}86 \cdot 5 \\
(77 \cdot 0-96 \cdot 0)\end{array}$ & $\begin{array}{l}66 \cdot 6 \\
(53 \cdot 7-79 \cdot 5)\end{array}$ & $\begin{array}{l}72 \cdot 1 \\
(58 \cdot 6-85 \cdot 6)\end{array}$ \\
\hline Freedom from CABG (\%) & $\begin{array}{l}98 \cdot 4 \\
(95 \cdot 2-100)\end{array}$ & $\begin{array}{l}98 \cdot 1 \\
(94 \cdot 3-100)\end{array}$ & $\begin{array}{l}92 \cdot 2 \\
(84 \cdot 6-99 \cdot 8)\end{array}$ & $\begin{array}{l}90 \cdot 8 \\
(81 \cdot 9-99 \cdot 7)\end{array}$ \\
\hline $\begin{array}{l}\text { Freedom from repeat } \\
\text { PTCA }(\%)\end{array}$ & $\begin{array}{l}87 \cdot 1 \\
(78 \cdot 6-95 \cdot 6)\end{array}$ & $\begin{array}{l}90 \cdot 4 \\
(82 \cdot 2-98 \cdot 6)\end{array}$ & $\begin{array}{l}79 \cdot 8 \\
(69 \cdot 3-90 \cdot 3)\end{array}$ & $\begin{array}{l}83 \cdot 8 \\
(73 \cdot 2-94 \cdot 4)\end{array}$ \\
\hline $\begin{array}{c}\text { Freedom from CABG/ } \\
\text { repeat PTCA }(\%)\end{array}$ & $\begin{array}{l}85 \cdot 8 \\
(76 \cdot 6-94 \cdot 4)\end{array}$ & $\begin{array}{l}88 \cdot 5 \\
(79 \cdot 6-97 \cdot 4)\end{array}$ & $\begin{array}{l}73.7 \\
(61.8-85.6)\end{array}$ & $\begin{array}{l}76 \cdot 8 \\
(64 \cdot 3-89 \cdot 3)\end{array}$ \\
\hline
\end{tabular}

Values are percentages ( $95 \%$ confidence interval). MI, myocardial infarction; CABG, coronary artery bypass surgery.
Figure 1 Cumulative total and event free survival for all 62 patients. $D$, freedom from death; $D / M I$, freedom from death and myocardial infarction, $D / M I / C A B G$, freedom from death, myocardial infarction, and bypass surgery;

$D / M I / C A B G / P T C A$ freedom from death, myocardial infarction, angioplasty. bypass surgery, and repea

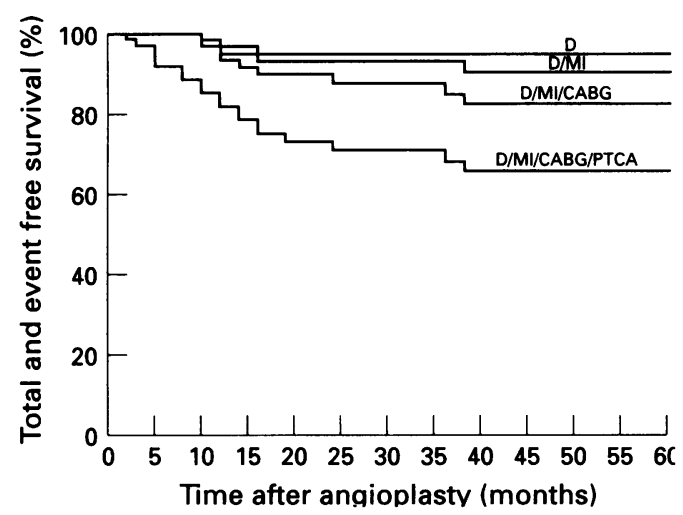

Figure 2 Cumulative event free survival according to outcome of initial angioplasty. $M I$, myocardial infarction; $C A B G$, coronary artery bypass grafting; PTCA, repeat coronary angioplasty.

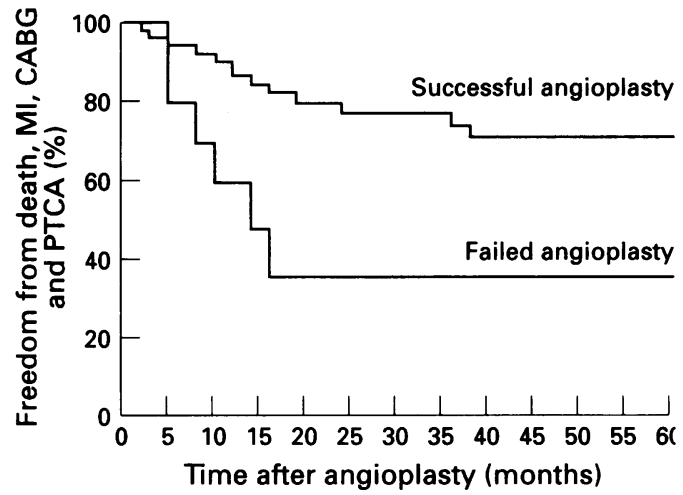

Time after angioplasty (months)

Figure 3 Angina grade before coronary angioplasty (PTCA) and at census in 58 survivors $(P<0.001)$.

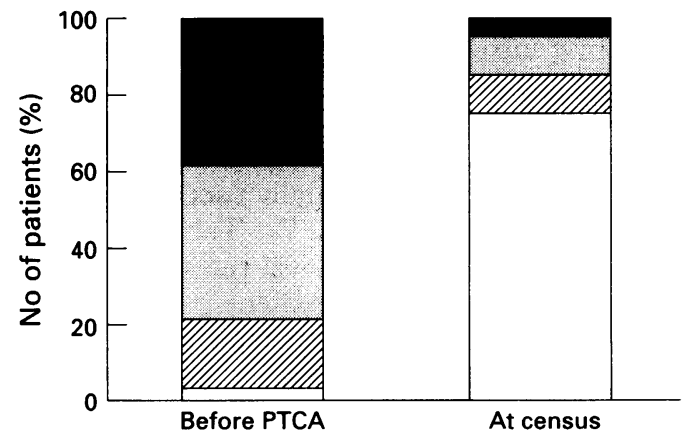

rates according to outcome of initial angioplasty. At census, of the 58 survivors, 31 (53\%) were asymptomatic, 19 (33\%) had mild angina, and only eight (14\%) complained of angina grade III or IV ( $P<0.001)$ (fig 3). Forty four patients (76\%) improved by at least two angina grades.

INCIDENCE OF A THIRD CLINICAL RESTENOSIS Repeat coronary angiography was performed in $26(46 \%)$ of the 56 patients who had initially successful angioplasties for recurrence of symptoms, or reversible ischaemia documented on symptom limited treadmill exercise tests. Continued success was present in eight patients (31\%) and angiographic restenosis was present in $18(69 \%)$ (including the patient who died from coronary artery bypass surgery for restenosis). Of the remaining 30 patients who did not undergo repeat angiography, two suffered cardiac death and two had a non-fatal myocardial infarction. The remainder were asymptomatic and had a negative exercise test at follow up except for one patient who had $1 \mathrm{~mm}$ ST segment depression at peak exercise. Hence, the total number of patients with a clinical restenosis was $22(39 \%)$.

\section{DETERMINANTS OF A THIRD CLINICAL} RESTENOSIS

Univariate analysis of 32 patient, lesion, and procedure related variables showed that restenosis was more common in patients who presented with unstable angina $(70 \% v 33 \%$, $P=0.03$ ), and in those where the time interval from the second to the third angioplasty was $\leqslant 5$ months ( $59 \% v 19 \%, P=0.002)$. The mean (SD) time interval from the second to the third angioplasty was $4 \cdot 8(2 \cdot 9)$ months in patients who subsequently developed a third restenosis and $7 \cdot 7(4 \cdot 7)$ months in those who did not $(P=0.03)$. Multiple stepwise logistic regression analysis identified the time interval between the second and the third angioplasty as the only independent predictor of restenosis $(P=0.004)$. None of the other variables analysed contributed significantly to this regression model.

\section{ANGIOPLASTY FOR A THIRD RESTENOSIS}

Procedural success was achieved in eight $(89 \%)$ of the nine patients who underwent a fourth coronary angioplasty for a third restenosis. One patient needed emergency coronary bypass surgery. There were no procedural deaths or myocardial infarctions. The eight patients who had a successful fourth angioplasty were followed up for a median (range) of 33 (8-68) months. There were no late deaths, myocardial infarctions, or coronary artery bypass grafting. At census, four patients were asymptomatic and four suffered only mild angina pectoris (grade I). Of the three patients who underwent repeat angioplasty for new coronary lesions, two had a successful procedure and one died as a result of the procedure. 


\section{Discussion}

The long-term efficacy of PTCA has been hampered by the problem of restenosis. ${ }^{1-3}$ The management of patients with recurrent restenosis has become a common but difficult clinical problem with the expansion of the indication for coronary angioplasty. Because its efficacy has been well documented, performance of a second angioplasty after the first restenosis has become routine clinical practice. $^{4-10}$ Whether further restenosis should be treated with angioplasty or coronary artery bypass surgery is less certain. This study aimed to examine the efficacy of a third angioplasty when two previous procedures were followed by restenosis.

\section{SHORT-TERM RESULTS}

The success and complication rates in this study were encouraging, and did not differ from the rates usually reported for first angioplasties. ${ }^{20-22}$ Other studies of coronary angioplasty for a second restenosis have reported clinical success rates of $92-97 \%$, consistent with the $90 \%$ in our study. ${ }^{11} 1415$ Procedural mortality ranging from 0 to $2 \cdot 7 \%$, myocardial infarction rates ranging from 0 to $2 \cdot 8 \%$, and emergency bypass surgery rates ranging from 0 to $4.9 \%$ have also been reported (table 3 ). In the present study, the corresponding mortality, myocardial infarction, and emergency bypass surgery rates were $0 \%, 1.6 \%$ and $1.6 \%$, respectively. The favourable results may reflect the highly selected population in these studies, in that these patients have already had two previous successful procedures at the target site, or it may be the result of differences in the physical properties of restenotic lesions compared with those of primary lesions. ${ }^{14}$

\section{LONG-TERM RESULTS}

Although angioplasty for recurrent restenosis is technically feasible, the procedure must be associated with short- and long-term symptomatic improvement to be judged as clinically successful. The efficacy of any revascularisation procedure is defined by the clinical events and the patient's functional status. It was not possible to determine the specific physiological and prognostic implications of coronary angioplasty of the coronary segment where recurrent restenosis had occurred, as other vessels were also dilated at the same time for complete revascularisation. In addition, the long-term outcome is likely to be influenced by the extent of native coronary artery disease, the extent of left ventricular dysfunction, and the restenosis rate. Furthermore, comparison between studies may be difficult because it is not possible to take account of differences in these baseline and procedural variations. Nevertheless, this study has shown that most patients with recurrent restenosis can be managed safely and effectively with repeat angioplasty.

The long-term results were encouraging with a 5 year survival rate of $95.0 \%$, and freedom from death and myocardial infarction of $90.9 \%$. Furthermore, angioplasty was associated with a marked improvement in angina status: $76 \%$ of patients had severe angina before angioplasty, but at census $53 \%$ were asymptomatic and $76 \%$ were improved by at least two angina grades. Although this favourable long-term outcome was in part contributed to by the need for a subsequent revascularisation procedure in $27 \%$ of patients, only $8 \%$ needed elective coronary artery bypass surgery. Freedom from death, myocardial infarction, and coronary artery bypass surgery was $83 \%$ at five years. In addition, the fourth angioplasty for a third restenosis was performed with an acceptable success rate of $89 \%$. Similar favourable longterm results have also been reported in earlier studies. $^{913}$

\section{INCIDENCE AND PREDICTORS OF RECURRENT} RESTENOSIS

The incidence of angiographic restenosis after a third angioplasty for a second restenosis remains high and was $69 \%$ in the present series. However, only $46 \%$ of patients returned for coronary angiography, usually for recurrent symptoms. The frequency of restenosis might have been lower had all patients returned for repeat angiography, irrespective of their symptomatic status. The clinical restenosis rate, defined as the recurrence of anginal symptoms or reversible ischaemia associated with angiographic evidence of restenosis, and included late cardiac deaths and myocardial infarctions occurring during follow up, was $39 \%$. The true angiographic restenosis rate probably lies between $39 \%$ and $69 \%$. Some studies have reported that the restenosis rate after a third angioplasty for a second restenosis is similar to that reported for a first and second angioplasty. ${ }^{14}$ Others have suggested that patients with multiple restenoses in the past are more likely to have restenosis in the future than those without this history. ${ }^{91315}$ The reported incidence of restenosis after a third angioplasty ranges from $34 \%$ to $48 \% .^{91523}$ The discrepancy may

Table 3 Other published results (in chronological order)

\begin{tabular}{llllllll}
\hline Reference & $\begin{array}{l}\text { No of } \\
\text { patients }\end{array}$ & $\begin{array}{l}\text { Procedural } \\
\text { success (\%) }\end{array}$ & $\begin{array}{l}\text { Death } \\
(\%)\end{array}$ & $\begin{array}{l}\text { AMI } \\
(\%)\end{array}$ & $\begin{array}{l}\text { CABG } \\
(\%)\end{array}$ & $\begin{array}{l}\text { Angiographic } \\
\text { restenosis (\%) }\end{array}$ & $\begin{array}{l}\text { Follow up } \\
\text { angiography (\%) }\end{array}$ \\
\hline Abi-Mansour, et al al $^{23} 1985$ & 17 & - & 0 & - & 0 & 24 & NA \\
Joly, et al ${ }^{11} 1988$ & 36 & 92 & 0 & $2 \cdot 8$ & $2 \cdot 8$ & 37 & 91 \\
Teirstein, et al al $^{13} 1989$ & 74 & 93 & $2 \cdot 7$ & 0 & $4 \cdot 0$ & 39 & 53 \\
Glazier, et al 1989 & 41 & 93 & $2 \cdot 4$ & 0 & $4 \cdot 9$ & 34 & NA \\
Dimas, et al $^{15} 1992$ & 49 & 94 & 0 & $2 \cdot 0$ & 0 & 57 & 61 \\
Bauters, al $^{14} 1993$ & 99 & 97 & 0 & 0 & 0 & 39 & 86 \\
\hline
\end{tabular}

AMI, acute myocardial infarction; CABG, emergency coronary artery bypass surgery; NA, not available. 
be accounted for by differences in the rate of angiographic follow up, especially low in patients who were asymptomatic, and in the definition of restenosis.

Although multiple variables have been associated with an increased first restenosis rate, the only variable found to be independently predictive of a third clinical restenosis in the present study was the time interval between the second and the third procedure. The finding that a short time interval between previous restenoses is predictive of future restenoses has been consistently reported by other investigators, although the reason remains unclear. Teirstein $e t a l^{13}$ have shown that the mean time interval between the second and the third angioplasty procedure was 4.9 months in patients who subsequently developed a third restenosis and 6.4 months in those who did not. Dimas et al ${ }^{15}$ have reported that the mean time interval between the first and the second angioplasty was 3.6 months in patients who subsequently developed a second restenosis and $6 \cdot 1$ months in those who did not. In the study by Quigley et $a l,{ }^{8}$ the corresponding mean time interval between the first and the second angioplasty was 4.5 months and $7 \cdot 1$ months. Black et al ${ }^{12}$ have shown that a time interval of $<5$ months between the first and the second angioplasty is predictive of a second restenosis. Bauters et al ${ }^{14}$ have shown that a time interval of $\leqslant 3$ months between the second and the third angioplasty is associated with recurrent restenosis. The disparate time intervals between the studies probably reflect differences in the delay between symptom recurrence as a result of restenosis and admission of patients for a repeat angioplasty. One possible explanation is that the short time interval between angioplasty reflects the increased tendency of the patient to develop intense smooth muscle cell proliferation. Another possibility is that the short time interval between successive angioplasties enhances the degree of neointimal hyperplasia in response to the injury caused by the balloon inflation, resulting in the development of early restenosis. ${ }^{24}$

\section{LIMITATIONS}

Although the study population consisted of a consecutive group that underwent coronary angioplasty for a second restenosis, the study is a retrospective analysis of data and is subject to all the limitations inherent in such a study.

The rate of repeat coronary angiography was low $(46 \%)$ as the procedure was performed only in patients who were symptomatic or had evidence of reversible ischaemia documented using non-invasive investigation. Therefore the exact angiographic restenosis rate cannot be determined.

\section{Conclusions}

The decision in choosing the mode of revascularisation in patients with recurrent restenosis depends on many factors, including the feasibility and safety of the procedure, the long-term efficacy, and patient or clinician preference. Our study has shown that a third coronary angioplasty for a second restenosis can be performed safely and effectively in selected patients, and provides good symptomatic relief and favourable long-term outcome. This suggests that multiple repeated angioplasty for recurrent restenosis can be accepted as an integral part of the overall coronary angioplasty revascularisation strategy and provides an attractive alternative to coronary bypass surgery in this group of patients. Although the incidence of restenosis remains high, the majority are relieved of symptoms by subsequent angioplasties. A high risk of subsequent clinical restenosis can be predicted from the time interval between the previous procedures, hence allowing an alternative mode of revascularisation to be considered in these patients.

New revascularisation technologies, such as stents and atherectomy, are currently under investigation. Randomised trials comparing directional atherectomy with balloon angioplasty have not shown any conclusive reduction in the rate of restenosis, or improvement in clinical outcome. ${ }^{2526}$ Results from randomised studies of de novo stent implantation using the Palmaz-Schatz device have demonstrated a reduction in restenosis rates compared with those of balloon angioplasty, but the risks associated with stenting are substantial. ${ }^{27} 28$ The need for intensive anticoagulant treatment requires prolonged hospitalisation, and results in bleeding problems, manifesting as a need for transfusion or major peripheral vascular complications. Furthermore, stent implantation is expensive, and the long-term results are not known. Further results should be awaited before drawing final conclusions on the merits of primary stenting. Until then, this study provides useful information in helping clinicians and patients to decide the most appropriate therapeutic course after recurrent restenosis has occurred.

1 Serruys PW, Luijten HE, Beatt KJ, Geuskens R, de Feyter $\mathrm{PJ}$, van den Brand $M$, et al. Incidence of restenosis after successful coronary angioplasty: a time related phenomenon. A quantitative angiographic study in 342 consecutive patients at $1,2,3$ and 4 months. Circulation 1988;77:361-72.

2 Leimgruber P, Roubin G, Hollman J, Cotsonis GA, Meier $\mathrm{B}$, Douglas JS, et al. Restenosis after successful coronary angioplasty in patients with single vessel disease. (73:710-7.

3 Kaltenbach M, Kober G, Scherer D, Vallbracht C. Recurrence rate after successful coronary angioplasty. Eur Heart $\mathcal{F}$ 1985;6:276-81.

4 Williams DO, Gruentzig AR, Kent KM, Detre K, Kelsey SF, To T. Efficacy of repeat percutaneous transluminal coronary angioplasty for coronary restenosis. $A m \mathcal{J}$ Cardiol 1984;53:32-35C.

5 Glazier JJ, Varricchione TR, Ryan TJ, Ruocco NA, Jacobs AK, Faxon DP. Factors predicting recurrent restenosis after percutaneous transluminal coronary balloon angioplasty. Am f Cardiol 1989;63:902-5.

6 Deligonul U, Vandormael M, Kern KM, Galan K. Repeat coronary angioplasty for restenosis: results and predictors of follow-up clinical events. Am Heart $\mathcal{f} 1989$; 117:997-1032.

7 Sugrue DD, Vlietstra RE, Hammes LN, Holmes DR Jr. Repeat balloon coronary angioplasty for symptomatic restenosis: a note of caution. Eur Heart $\mathcal{f} 1987 ; 8$ 697-701.

8 Quigley PJ, Hlatky MA, Hinohara T, Rendall DS, Perez 
JA, Phillips HR, et al. Repeat percutaneous transluminal coronary angioplasty and predictors of recurrent restenosis. Am ₹ Cardiol 1989;63:409-13.

9 Glazier JJ, Varricchione TR, Ryan TJ, Ruocco NA, Jacobs AK, Faxon DP. Outcome in patients with recurrent restenosis after percutaneous transluminal balloon angioplasty. Br Heart f 1989;61:485-8.

10 Meier B, King SB III, Gruentzig AR, Douglas JS, Hollman $\mathrm{J}$, Ischinger $\mathrm{T}$, et al. Repeat coronary angioplasty. $\mathcal{F} \mathrm{Am}$ Coll Cardiol 1984;3:463-6.

11 Joly P, Bonan R, Palisaitis D, Cequier A, Crepeau J, Cote $\mathrm{G}$, et al. Treatment of recurrent restenosis with repeat percutaneous transluminal coronary angioplasty. $A m \mathcal{F}$ percutaneous transluminal

12 Black AJR, Anderson HV, Roubin GS, Powelson SW, Douglas JS Jr, King SB III. Repeat coronary angioplasty: correlates of a second restenosis. $\mathcal{F}$ Am Coll Cardiol 1988; 11:714-8.

13 Teirstein PS, Hoover CA, Ligon RW, Giorgi LV, Rutherford BD, McConahay DR, et al. Repeat coronary angioplasty: efficacy of a third angioplasty for a second restenosis. ₹ Am Coll Cardiol 1989;13:291-6.

14 Bauters C, McFadden EP, Lablanche JM, Quandalle P, Bertrand ME. Restenosis rate after multiple percutaneous transluminal coronary angioplasty procedures at theous transluminal coronary angioplasty procedures at the same site. A quantitative angiographic study in procedure for a second restenosis. Circulation 1993;88: procedure

15 Dimas AP, Grigera F, Arora RR, Simpfendorfer CC, Hollman JL, Frierson JH, et al. Repeat coronary angioplasty as treatment for restenosis. $\mathcal{f} \mathrm{Am}$ Coll Cardiol 1992;6:1310-4

16 Campeau L. Grading of angina pectoris. Circulation 1976; 54:522-3.

17 Sowton E, Timmis AD, Crick JCP, Griffin B, Yates AK, Deverall $P$. Early results after percutaneous transluminal coronary angioplasty in 400 patients. Br Heart $\mathcal{F} 1986$; 56:115-20

18 Ellis SG, Vandormael MG, Cowley MJ, DiSciascio G, Deligonul U, Topol EJ, et al and the Multivessel Angioplasty Prognosis Study Group. Coronary morphologic and clinical determinants of procedural outcome with angioplasty for multivessel coronary disease. Circulation 1990;82:1193-202.

19 Myler RK, Shaw RE, Stertzer SH, Hecht HS, Ryan C, Rosenblum J, et al. Lesion morphology and coronary angioplasty: current experience and analysis. $\mathcal{f} \mathrm{Am}$ Coll Cardiol 1992;19:1641-52.

20 Bertrand ME, Marco J, Cherrier F, Schmitt R, Gasper $\mathrm{PH}$, Puel J, et al. French percutaneous transluminal coronary angioplasty (PTCA) registry: four years experience [abstract]. ₹ Am Coll Cardiol 1986;7:21A.

21 Holmes DR Jr, Vlietstra RE, Smith HC, Vetrovec GW, Kent KM, Cowley MJ, et al. Restenosis after percutaneous transluminal coronary angioplasty (PTCA): a neous transluminal coronary angioplasty (PTCA): a
report from the PTCA registry of the NHLBI. $A m g$ Cardiol 1984;53:77-81C.

22 Dangoisse V, Guiteras Val P, David PR, Lesperance J, Crepeau J, Dyrda I, et al. Recurrence of stenosis after successful PTCA [abstract]. Circulation 1982;66(suppl II):II-331.

23 Abi-Mansour P, Whitworth HB, Hoffmeister J, Douglas JS, King SB. Initial and late outcome after a third coronary angioplasty (PTCA) for recurrent native coronary restenosis [abstract]. Circulation 1985;72 (suppl III):III-141.

24 Schneider JE, Santoian EC, Gravanis MB, Cipolla GD, Tarazona N, Scott NA, et al. Timing of repeat balloon injury influences intimal hyperplasia in a swine model of coronary restenosis. In: Topol EJ, ed. Proceedings of Restenosis Summit IV; Cleveland, OH, 1992:21.

25 Topol EJ, Leya F, Pinkerton CA, Whitlow PL, Hofling B, Simonton CA, et al for the CAVEAT Study Group. A comparison of directional atherectomy with coronary angioplasty in patients with

26 Adelman AG, Cohen EA, Kimball BP, Bonan R, Ricci $\mathrm{DR}$, Webb JG, et al. A comparison of directional atherectomy with balloon angioplasty for lesions of the atherectomy with balloon angioplasty for lesions of the left anterior descendin

27 Serruys PW, de Jaegere P, Kiemeneji F, Macaya C, Rutsch W, Heyndrickx G, et al for the BENESTENT Study Group. A comparison of balloon-expandable-sten implantation with balloon angioplasty in patients with coronary artery disease. $N$ Engl $f$ Med 1994;331: 489-95.

28 Fischman DL, Leon MB, Baim DS, Schatz RA, Savage MP, Penn I, et al for the Stent Restenosis Study Investigators. A randomized comparison of coronarystent placement and balloon angioplasty in the treatment of coronary artery disease. $N$ Engl $f$ Med 1994;331: 496-501. 